International Journal of Linguistics, Literature and Translation

ISSN: 2617-0299 (Online); ISSN: 2708-0099 (Print)

DOI: 10.32996/ijltt

Journal Homepage: www.al-kindipublisher.com/index.php/ijltt

\title{
Effective Language Teaching and Learning Process in EFL Classroom Situation: A Case Study
}

\section{Samah BENZERROUG 8 (iD)}

Senior Lecturer, Ecole Normale Supérieure de Bouzareah (ENSB), Algeria

$\triangle$ Corresponding Author: Samah BENZERROUG, E-mail: benz-sam@hotmail.fr

\section{ARTICLE INFORMATION}

Received: July 12, 2021

Accepted: August 05, 2021

Volume: 4

Issue: 8

DOI: $10.32996 /$ ijllt.2021.4.8.8

\section{KEYWORDS}

Teaching, learning, process, foreign language, EFL classroom learners competencies, efficiency

\section{ABSTRACT}

The goal of teaching and learning a foreign language, in general, has shifted from putting emphasis on the product of teaching to the process of teaching and learning and the accompanying classroom conditions. This development in foreign language teaching pedagogy stresses the importance of the classroom environment in enhancing the individual's learning styles and motivation to acquire the language, skills and components. Therefore, it is essential that every language class is directed to equip the learners with the necessary language strategies to achieve language proficiency by considering their needs and interests. This is why, teachers are always looking for updated ways and techniques to develop the student competencies in listening, speaking reading, writing, vocabulary and grammar. In this context, the present research was conducted more specifically to examine to what extent can the role of the teacher and the quality of the teaching and learning process be effective in developing the learners' skills and competencies and promoting the EFL classroom situation. In addition, the different pedagogical tools and phases that are implemented in English language teaching in the Algerian school will be presented and analyzed in this paper.

\section{Introduction}

Teaching English as a foreign language demands to create a fostering learning environment that involves the teacher, the learner and the language skills and components to be developed. It prepares the learner to be in active interaction with the elements of the learning situation and acquire different experiences. These aspects have a dynamic specificity and include a language activity. The purpose is to let learners acquire knowledge, skills, values, orientations and tendencies .

The process of teaching and learning is interactive in a classroom situation. It is then a relationship and a situation between two "poles" : a teacher and a learner. The teacher gives a sum of knowledge, a sum of behaviours, attitudes and values, and the learner receives, internalises, reacts and eventually uses them. However, an efficient learning and an effective teaching presuppose favourable conditions : teacher, learners, knowledge and behaviours, environment and interaction .

Hence the process of interaction between the teacher and the learner and among the learners themselves is an essential and determinant factor in an educational situation .In order to get a feedback about his teaching, the teacher needs an active communication and participation on the part of the learners . Language teaching and learning are essentially based on interaction and communication. Since communication derives from interaction (Hudson 1980:81), learning a language is learning to communicate and interact. Therefore, interaction and communication are closely related characteristics of language:

"Language is the institution whereby humans communicate and interact with each other by means of habitually use oral-auditory arbitrary symbols ." (Lyons 1981:4)

\section{K C AL-KINDI CENTER $\mathbf{R}$ D FOR RESEARCH AND DEVELOPMENT} Your gateway to world-class research

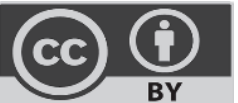

Published by Al-Kindi Center for Research and Development, London, United Kingdom. Copyright (c) the author(s). This open access article is distributed under a Creative Commons Attribution (CC-BY) 4.0 license 
With this prominent shift within the field of language learning and teaching, a greater emphasis is put nowadays on the teaching and learning process itself. The purpose of this research is; therefore, to analyze language teaching and learning relationship and emphasize the importance of the quality of this process as well as the role of the teacher in helping learners develop their strategies and competencies. The Study aims to analyse the way EFL material is presented to the EFL learners in the Algerian school and investigate its efficiency.

\section{Literature Review}

\subsection{Teaching and Learning Relationship}

Teaching is one of the most important activities that helps people gain the knowledge and attitudes to be responsible citizens (The World Book Encyclopedia,1983:144). In general terms, teaching is the process by which a person helps other people to learn. It is a set of activities with various aspects and dimensions : it does not include knowledge only, but reactions and gestures when conveying knowledge, asking questions, explaining, clarifying, listening, encouraging , discussing , convincing and being convinced. Teaching is; therefore, the action of guiding, assisting the learners to acquire new vocabulary, skills, and behaviour, and to enable them interact and communicate.Furthermore, its ultimate purpose is to help the overall development of their personalities :their cognitive, social and psychological aspects. The process of teaching has to be well arranged and planned in order to reach its objective; that is learning. Consequently, the teacher has to set a teaching strategy and to provide good conditions within which learning may take place and the learner is actively involved in his learning process to develop the different aspects of his personality .

Learning, on the other hand, is the process of translating new knowledge and skills into behaviour. Three domains of learning are identified :

-cognitive; concerning the theories, facts, concepts and problem solving .

-affective; related to feelings and emotions.

-psychomotor; referring to new skills and new way of doing things (Davis 1994:12).

Learning is the process by which changes in behaviour result from experience or practice. By behaviour, is meant any response that an organism makes to its environment. Thus behaviour includes actions, emotions, thoughts and the responses of muscles and glands. Learning can produce changes in any of these forms of behaviour ( The World Encyclopedia 1983:144) . Learning, then, means the adaptation of the individual to his environment. In other words, it is the ability to adapt the acquired knowledge and experiences to real situations .In order to ensure efficient learning, teaching should be geared towards the implication of the learner as a central element in the educational process. The learner must feel the pleasure to learn. Thus, the learner's role in his own learning should be an integral part of any teaching strategy and the teacher ought to select and use the teaching methods and techniques that would encourage learner's active participation .

Moreover, individual relations are important for successful and efficient interaction in the classroom. Positive relations between the teacher and the learner, and the affectionate types and relations arise the learners' motives to do their best in their studies. Psychological studies have shown the possibility to foresee the learner's reactions and his affectionate behaviour as regards his reaction to his teacher. That is why the latter should be aware enough of the individual phenomena. This, require a good mastery of talking with pupils in order to increase their motives for learning and take pleasure in free learning. The teacher can realize this when he avoids the arousal of negative feelings to mention anxiety and anger or when he develops positive feelings such as respect or rewards.

Language teaching and learning are in their objectives essentially based on interaction and communication. The purpose of language learning and teaching is associated with the use of that language in a real communicative situation. There is no doubt that language helps people to interact and promotes mutual understanding, tolerance and respect for the cultural identity and values of others (Lyons 1981:230).Besides, success in the international world of commerce, trade and business ,in general, is becoming more and more dependent on foreign language learning, especially English .

Language plays an determinant role in educating people (The World Book Encyclopedia 1983:143).It is the means by which learners firstly acquire knowledge and skills and are able to interact and communicate by providing them with a "natural context for language use " (Larsen Freeman 2000:144). It constitutes ,therefore, a potent medium in developing the learners' personality, cognitively, socially and psychologically. Cognitively, learners are enabled to express their thoughts and develop their thinking skills and abilities to observe, organise, analyse and criticize knowledge, to think creatively, etc. Psychologically, they can express their feelings and emotions. Socially, language makes a person feel that he belongs to a particular community and interacts positively with its members .

As stated before, language teaching and learning are necessary for the development of the learners' personality, it is then 
important to make the teaching and learning process effective. For a successful and efficient interaction in the classroom, effective teaching strategies should be sought. Therefore, the selection of appropriate teaching methods and techniques in the process of teaching becomes essential.

It is difficult to determine a precise concept for effective teaching because of the various and numerous conditions special to the teacher and the teaching situation itself. Therefore, effective teaching represents a complex operation and a dynamic function . It stands for a teaching theory based on the following assumptions ( Referential Guide Service 2001:16) :

-Teaching aims at creating a change in the learner's behaviour and thinking .

- Teaching is a logical operation that can be made better by examining its components in an analytic way .

-The teacher is the most active axe who shapes the learner's behaviour for he puts and fulfils the plan .

-The teacher's teaching behaviour has an influence on the learner's behaviour and on the process of learning .

If teachers' roles vary according to the approach adopted, it is obvious that the teacher will want to know where s/he really stands in the teaching approach. The modern learner-centred approach to language teaching and learning does not seek the teacher's subservience as it is the case for the previous approaches which are rather teacher-centred (Harmer 2001:82). Neither does it seek to substitute itself to the teacher as regards decision making in class, the organisation in the classroom and so on . All it demands is to make the best use of it according to its principles and characteristics .

Such characteristics of the Approach naturally requires 'teacher in action', in other words, teachers who will draw on their professional skills, skills in subject matter, in methodology, decision-making and social skills of various sorts to enable the learners to be language achievers. However, to be 'teachers in action' does not mean a return to that ancient role of 'drill sergeant' peculiar to the Audio-lingual Method. The emphasis on cognition also demands a style of teaching based on reflection. Reflection on what, why and how the teacher should teach / or s/he is teaching in the classroom ( reflection in action )implies, among other things, planning ahead the lessons, fixing objectives for each lesson, adjusting the teaching strategies so as to cope with the unexpected, giving time to the learners to reflect on what they are learning and checking whether the objectives are reached at the end of each lesson, sequence and unit .

The socio-cognitivist strain of the learner centred approach demands that the teacher ceases playing the simplistic role of ' transmitter' of knowledge and the learner that of the 'receiver' of knowledge ( about language and its literature as it is the case, for example, in the Grammar-Translation Method ). Instead, her/his role is to facilitate the process of language acquisition through the development of appropriate learning strategies like hypothesis-making and hypothesis-testing .S/he stands as a resource person whose help is sought whenever learners meet with special difficulties as they develop/construct by themselves their competencies wherein the teacher plays the role of director setting stage directions, assessing, and giving feedback to the players in order to bring the final touch to their performance.

Effective language teaching and learning process cannot take place unless some conditions are provided.

\subsection{Lesson Plan}

A key aspect of effective teaching is having a plan for what will happen in the classroom each day. Creating such a plan involves setting realistic goals, deciding how to incorporate course textbooks and other required materials, and developing activities that will promote learning .

" A good communicative lesson should:

-derive input from authentic sources

-involve learners in problem solving activities

- incorporate tasks which relate to learners' real life communicative needs

-expose learners to the language as system

-encourage learners to develop skills in learning how to learn ..."

(Nunan 2003:132).

A lesson plan gives the lesson a framework, an overall shape. Planning helps the teachers to focus their minds, to think about where they are going and give them time to have ideas for coming lessons. It helps them to have something to refer to in the middle of their class, and gives learners confidence; they know immediately whether a teacher has thought about the lesson, and they respond positively to those that have .

Whatever the format of a plan is, it should contain at least the following components :

-The subject title, grade level and timing

-The objectives to achieve

It appeals also to the use of some teaching aids and materials which are needed for the lesson:

-Anticipated problems 
-The learning activities in which the learners will participate

-Methods and criteria for student evaluation

\subsection{Lesson Objectives}

Lesson objectives are most usefully stated in terms of what students will have done or accomplished at the end of the lesson . Stating objectives in this way allows both teachers and learners to know when the goals have been reached.To set lesson objectives, the teacher should first identify a topic for the lesson which will help in developing the objectives . The topic is generally determined by the curriculum and the textbook and is part of a larger thematic unit .

The topics are chosen according to the students interests and the availability of authentic materials at the appropriate level . Then, the teacher has to identify specific linguistic content, such as vocabulary and points of grammar, or language forms, to be introduced or reviewed and are connected in some significant way with the topic of the lesson . These are usually prescribed by the course book and the curriculum. After that, the teacher has to identify the specific communicative tasks to be completed by the students. The tasks should allow, but not require, students to use the vocabulary, grammar, and strategies presented in the lesson. The focus of those tasks should be topical and not grammatical. This means that it may be possible for some students to complete the task without using either the grammar point or the strategy presented in the first part of the lesson.

\subsection{Lesson Structure}

To reach the objectives mentioned above, a language lesson should include coherence and a variety of activities that combine different types of language input and output. Variety and coherence are necessary and beneficial for the learners since they are mare motivating and are more likely to result in effective language learning :

"The techniques imply that opportunity for students' interaction should

be provided for almost every step of the lesson." (Teacher's Book ,Getting Through 2006:10)

It is assumed that an effective lesson has five main phases (Referential Guide Service 2001:18) :

-Preparation

-Presentation

-Practice

-Evaluation

-Expansion / Consolidation

The five parts of a lesson may all take place in one class session or may extend over multiple sessions, depending on the nature of the topic and the activities. The lesson plan should outline who will do what, how , with what and in which part of the lesson .

\section{-Preparation Phase}

As the class begins, the teacher should give students a broad outline of the day's objectives and activities so that they know what to expect. S/he has to use a discussion or a homework review to elicit knowledge related to the grammar and language points to be covered, use comparisons with the native language to elicit strategies that students may already be using, and use discussion of what students do and /or like to do to elicit their knowledge of the topic they will address in communication activities .

\section{-Presentation Phase}

The teacher will move from preparation to the presentation of the linguistic and topical content of the lesson and relevant learning strategies S/he will present the strategy first if it helps the students to absorb the lesson content. The presentation phase provides the language input that gives the students the foundation for their knowledge of the language. Input comes from the instructor (the teacher ) or the textbook. Structured input is an important part of the presentation, in which students practise the form that the teacher has presented. In structured output, accuracy of performance is important, the output is designed to make learners comfortable in producing specific language items recently introduced .

\section{-Practice Phase}

In this part of the lesson, the focus shifts from the teacher as a presenter to the students as completers of a designated task . Students work individually, in pairs, or in small groups on a topic-based task with a specific outcome. The teachers observes the students as they work and acts as a resource or advisor when the students have questions that they cannot resolve by themselves. In their work, students move from structured output to communicative output, in which the main purpose is to complete a communicative task. Language becomes a tool, rather than an end itself. Learners have to use some or all of the language that they know along with varied communicative strategies. 


\section{-Evaluation Phase}

After the learners have completed the communicative task by using the linguistic content and the learning and communication strategies, time comes for the teacher to assess her / his students work. Assessment is useful for the following reasons (Document d'Accompagnement du programme d'Anglais 2AS 2006:131):

- It reinforces the material that was presented earlier in the lesson.

-It provides an opportunity for the students to raise questions of usage and style.

-It enables the teacher to monitor individual student comprehension and learning.

\section{-Expansion Phase}

Expansion activities allow students to apply the knowledge they have acquired in the classroom to situations outside it . They include out-of-class observation assignments, in which the teacher asks students to find examples of something or to use a strategy and then report

back .

\subsection{Lesson Materials and Activities}

The materials for a specific lesson will fall into two categories : those that are required such as textbooks and lab materials, and authentic materials that the teacher incorporates into classroom activities. For required materials, the teacher should determine what information must presented in class and which for out-of-class work. S/he should use materials that are genuinely related to realistic communication activities, s/he also should use the textbook as a support to achieve the objectives, and not to follow it slavishly:

"Course materials for English should be seen as the teacher's

Servant and not his master."( Garinger 2001).

Truly authentic communication tasks have several features. They involve solving a true problem or discussing a topic of interest, and require using language to accomplish a goal, not using language merely to use language. Besides, they allow students to use all of the language skills they have, rather than specific forms or just the vocabulary learnt before, and to self-correct when they realize that they need to.

It should be mentioned that the use of new technologies like computer, Internet, video , CD Rom ,and other audio- assisted programmes in language teaching and learning classrooms can create more interesting learning environment (Cela, 1994:3) with facilities to gather and understand information .

"The use of information technology can motivate and give pleasure to pupils of all ages. Both boys and girls often achieve levels of experience with Information Technology, that surprises their teachers and themselves." (Programme d'Anglais du Première Année Secondaire 2005:6).

\section{Methodology}

This study is an exploratory research which investigates the methods that are used in teaching English as a foreign language in the Algerian schools. It highlights the teaching and learning process and the development of the basic receptive and productive language skills and components on the basis of the Competency-Based Approach (CBA) .

\subsection{Teaching Listening and Speaking in the EFL Classroom}

Listening and speaking skills are taught together in one sequence because any communicative situation involves a 'speaker' and a 'listener' . Listening is recognizing, understanding and interpreting ;however, speaking consists of reacting , articulating and producing. Listening comprehension plays an extremely important role in the foreign language acquisition and in the development of speaking abilities. Speaking feeds on usually, one person speaks, and the other responds by means of the listening process .

"While listening, learners must comprehend the text by retaining

information in memory, integrate it with what follows, and continually

adjust their understanding of what they hear in the light of prior knowledge

and of incoming information" (Shuman 1997:12).

\subsubsection{Teaching Listening in the EFL Classroom}

As stated before, Speaking is closely related to listening which is the basic mechanism through which the rules of language are internalized .Far from passively receiving and recording aural input, learners actively involve themselves in the interpretation of what they hear, bringing their own background knowledge and linguistic knowledge to bear on the information contained in 
the aural text . CBA facilitates the process of learning by presenting programmes in an attractive way and by using the new means of information and technology. For instance, through the use of CD- ROMS or tape records, the learners are exposed to many kinds of situations and accents as well as voices. They are exposed to a varied range of authentic speech with different registers, accents, intonations, rhythms and stresses. Besides, the language is used in the context of real learning (Ernestova 1989:5).

Through listening to the teacher's voice and the tapes, learners are exposed to different varieties and accents which give them a better idea of the world language which English has become. They also will get information not only about grammar and vocabulary but also about pronunciation, rhythm, intonation, pitch. This means that for a first listening, the task needs to be general to get the gist. Later listening; however, may focus on details .

Activity is important in testing listening comprehension and it does not appeal for linguistic production. Students are not provided with a visual support that could facilitate the tasks, so they rely only on sounds and flow of words to get meaning. As stated before, listening does not need linguistic production; therefore, learners should not be asked to produce full sentences , but they may be asked to : circle the right answers, fill in gaps, reorder main ideas, match ideas with their corresponding paragraphs, complete tables, say whether sentences are true or false, etc .

\subsubsection{Teaching Speaking in the EFL Classroom}

Speaking is an important skill through which we can assess pupils' progress in terms of their accomplishments in spoken communication .In CBA, teachers help their pupils develop speaking by providing authentic practice that prepares them for real life communication situations. They also help them develop the ability to produce grammatically correct, and logically connected sentences that are appropriate to specific contexts by using acceptable pronunciation .

The goal of teaching Speaking skill is communicative efficiency .Learners should be able to make themselves understood, using their current proficiency to the fullest. They should try to avoid confusion in the message due to faulty pronunciation, grammar, or vocabulary, and to observe the social and cultural rules that apply each communicative situation .

We should recognize that speaking involves three areas of knowledge :

*Mechanics (pronunciation, grammar, ad vocabulary): using the right words in the right order

with the correct pronunciation .

*Functions : knowing when clarity of message is essential and when precise understanding is not required.

*Social and cultural rules and norms: understanding how to take into account who is speaking to whom, in what circumstances, about what, and for what reason .

\subsection{Teaching Reading and Writing in the EFL Classroom}

Reading and writing are related to each other .Reading is an important tool for generating ideas. It could be used as a prewriting activity that exposes the learner to vocabulary, conventions, idioms, etc, .Besides, a story, a novel, a poem can generate ideas for a topic in the writing class .

\subsubsection{Teaching Reading in the EFL Classroom}

Reading is one of the basic language skills that, together with speaking, listening and writing form an indivisible whole. It is considered as an active and receptive skill that aims at predicting and interpreting information (Venkateswaran 1995:88).In the reading comprehension stage, students are provided with a variety of exercises always ending with some sort of note taking and summarizing .

Traditionally, the purpose of learning to read in a language has been to have access to the literature written in that language . The traditional approaches assume that students learn to read a language by studying its vocabulary, grammar and sentence structure. The Communicative Approach to language teaching has given birth to a different understanding of the role of reading in language classroom and the types of texts that can be exploited in instruction. When the goal of instruction is communicative competence, every day materials such as newspaper articles, and travel and tourism web sites become appropriate classroom materials because reading them is one way communicative competence is developed.

The content of the reading passage must be consistent with the reader's pragmatic knowledge or his expectations based on his world knowledge .Before a learner reads, he will have certain basic assumptions and expectations about communication such as what is important and relevant to that particular discourse. For the reader to make the appropriate inference, the text must 
have a sense of correctness and appropriateness in terms of form and content because when while reading, he tries to integrate information in the text with the existing knowledge.

\section{- Reading Purpose}

Reading is an activity with a purpose and serves a function. A student may read in order to gain information or verify existing knowledge, or in order to critique the writer's ideas or writing style.A student may also read for enjoyment or to enhance knowledge of the language being read .Moreover, reading texts provide opportunities to study language ( vocabulary , grammar, punctuation, and the way we construct sentences, paragraphs and texts ).

\section{-Reading Process}

Reading is an interactive process that goes on between the reader and the text resulting in comprehension. At the first stage of this process, the aim of the students in reading activities is to learn to decipher the message conveyed in a sentence , thus they should be provided with the basics of the language : its pronunciation, vocabulary, grammar, sentence structure ,etc. As learners progress with the basic elements of English language, they enter the second stage which is that of reading for the acquisition of information .

The reading process includes two transitions; the first one from words to sentences (reading at the syntactical level ) , and the second one from sentences to the whole text ( reading at the textual level). The text presents letters, words, sentences and paragraphs that encode meaning, and it is up to the learner to use his knowledge, skills and strategies to decode that meaning . While reading, the students should learn to identify the main idea of each paragraph and to devote part of their attention to the analysis of logical relations between sentences and paragraphs.

\section{-Reading Skills and Strategies}

When reading a text, students need to be able to develop a number of Skills which will help them decode meaning gradually . They need to be able to skim through the text to identify the gist and the main idea of each paragraph . In other words, they read the passage for global understanding at the text level, then at the paragraph level. Afterwards, they need to be able to scan the text to find a particular piece of information. They also need to be able to read for details in order to extract specific information contained in each paragraph. Learners examine the text carefully and move gradually to details. They are therefore guided through the activities to get a clear picture of the text .

\section{- Reading Classroom Activities}

Reading activities are organized into three main phases: pre-reading phase ( before you read), while reading phase ( as you read) and post reading phase ( after you read).

*Pre -reading phase : in this stage, questions should be used by the teacher as a means of checking how much learners know about the topic, and also as a means of helping them better understand the passage they are going to read . Such pre-reading questions on the text often bring about amazing results because they introduce the topical lexis, increase the students' interest in the subject to be read, and enable them to read with a 'purpose'. In this stage of learning, learners are engaged in the activity, but accuracy is not expected at this level since they are going to discover by themselves the right answers, and then to correct the mistakes in the next phase.

*While-reading phase : in this stage, students read in order to check out their predictions and correct their answers as well . Besides, they develop the ability to analyze the most important information so that they can read more quickly and efficiently .

*Post-reading phase : at this level, learners are expected to be able to synthesize the most relevant information and therefore summarize the reading passage its breaking down in the while-reading phase .

\subsubsection{Teaching of Writing in the EFL Classroom}

The current English language curriculum encourages the students and gives them opportunities to produce written texts. Years ago, writing was characterized by an approach that put emphasis on linguistic forms. Speech was primary, and writing served to reinforce oral patterns of the language. Writing took the form of sentence drills, transformations, completions, imitations and substitutions. It tested the exact application of grammatical rules, and focused on the written products composed by the students. Nevertheless, the focus on the did not take into consideration the act of writing, and the students were not allowed freedom to create their own compositions. In other words, content was neglected, and emphasis was put in the form and structure of writing rather than on how writers create a written piece .

With the implementation of CBA, the students in the English Language classroom no longer do the same types of activities that they did in the past. The attention to the writer as language learner and creator of a text, has led to the adoption of new class tasks and projects characterized by the use of journals, drafts, collaborative writing, revision and attention to content as much 
as form. The students can explore ideas first ; they are also allowed time and opportunities to choose topics of interest . Moreover, they can use personal experience to write about what concerns them generates,generate ideas, get feedback, share their writing with peers, revise and finally edit their work . Linguistic accuracy is no longer emphasized from the start, but is delayed until the learner has explored ideas .

It should be mentioned again that with the reform of the Algerian Educational System, the final objective of EFL teaching is that the students should be able to produce a piece of writing of about fifteen lines at least through CBA.And it is known that writing skill is essential for succeeding in university and job market .

Writing is considered as a productive skill that complements the other language skills and helps the learners express their ideas and thoughts in written form. Writing is dealt with in CBA through situations of integration that give the students the opportunity to re-invest in a meaningful way what was dealt with during the previous sequences. They use the linguistic elements to express themselves and produce a piece of writing. For the teacher, the situation of integration is a way to assess the learners' learning .

\subsection{Teaching Grammar in the EFL Classroom}

The teaching of grammar plays a central role in language teaching. Grammar is the body of rules which underline a language . It would include rules which govern the structure of words to form clauses and sentences without neglecting the meanings and functions these sentences have.

\subsubsection{The Introduction of an Inductive Method for Teaching Grammar}

The traditional approach to EFL teaching adopted a deductive method of teaching Grammar; the teacher usually makes learners identify the form of the language point provided in a context, then writes the examples on the board, explains and at last elicits the rule.After that the students are asked to practice the rule orally and in writing .

Some researchers argue that there is no harm in this procedure based on the traditional 'presentation-practice-production' pattern (Litz 2001). This method is however not communicative since it stresses the grammatical accuracy and pays a little attention to the functional value of the grammar point. Therefore students are given form based activities in which they manipulate the form without paying attention to meaning .

However, with the implementation of CBA, EFL teachers adopt the inductive method of teaching grammar in which they encourage students' involvement and lead them to identify the rules by themselves. The teacher is supposed to make the students identify the form of the language point in a given context, understand its meaning and use, and state the rule concerning form, meaning and use. The students are therefore engaged in meaning-based activities; they use the form to express something meaningful and grammatically correct. They are engaged in communicative activities to practice the structure being learnt .

The syllabus content is organized in such a way to stress the importance of meaning in over form . It takes into account learners' needs and interests and aims at understanding and producing significant messages. It also takes into consideration language functions and puts emphasis on the comprehension and production of diverse sorts of authentic messages in a significant context. The use of language in real communicative situations necessitates from the learners the interpretation and production of new sentences on the basis of the learned grammatical rules and lexical items of that language (Rivers 1970:140).

The study of grammar is subordinated to the development of language skills. So, it is essential to engage the learner in research for meaning within a context so that he can formulate his own messages afterwards (oral and/or written messages).

"If the learners are not given opportunities to explore grammar in context,

it will be difficult for them to see how and why alternative forms exist to

express different communicative meanings." (Nunan 1998:102).

EFL learners are given the opportunity to manipulate the rules concerning the functioning of language; rules that govern text coherence and progression.At this level, we no longer talk about formal teaching of grammar, but the latter is considered as a means to facilitate communication and expression because the major objective is enabling the learner to communicate and express himself correctly, clearly and easily either orally or in writing .

It is up to teacher to guide her /his students and help them discovering concepts and expressing them in their own language (inductive method). This method encourages the learner to discover and enables him to reflect, analyze and synthesize through comparisons and inferences. Once he assimilates the rules, he can state them explicitly. The inductive method is organized in three phases : 
-Phase one : observation of sentences, examples, counter-examples, texts, etc, in which the student is facing a problematic situation .

-Phase two : construction of rules that reveals functions of the text .

-Phase three : re-investment of language outcomes in production.

\subsection{Teaching Vocabulary in the EFL Classroom}

Teaching vocabulary is a very important element of teaching English because pupils, knowing more and more words,can better communicate with one another. It is one of the most important things in teaching foreign languages . In the Agerian EFL textbooks, teachers are provided with different interesting techniques in teaching vocabulary to make English lessons more exciting and motivating for students :

- Use of objects : the use of real objects in the classroom helps to make the meaning of words clear, the learners learn words by using concretes ( e.g. a pen, a postcard, a ball ,etc. ). The teacher may also use classroom environment : a chair, a table or a board.

- $\quad$ Pictures : may be the most useful aids in language teaching, since they rae used in different ways . There are pictures, blackboard drawings, wall pictures, charts, photos from magazines. Those aids are used to explain the meaning of words or to create a situation or concept

- Mime, Action and Gesture : this technique is useful for explanation of the actions and grammar items . Such concepts : jumping, smoking or the prepositions " from, on , to , under ,etc .) are easy items to explain through performing those actions

- Mime and action are of a great fun to learners who like acting and moving very much at this level .

- Contrast : it is usually used to show the similarities and differences between persons, ideas and things .

- Enumeration : this technique helps when any word is difficult to explain visually . We can say 'clothes' and explain this by enumerating or listing various items. The teacher may list a number of clothes like : a dress, a skirt, trousers, etc, and then the meaning of the word becomes clear.

- Explanation : this is such a technique which is assigned to be utilized with learners when they already have some knowledge of English. It is essential for the teacher to use the language that is comprehensible for the students while explaining certain words. Moreover, information about the frequency of the word should be provided.

- Synonyms : this technique relies on explanation of meaning of new word by giving other word, which students know and understand, and which means nearly the same. For example : little =small, big=huge, etc.

- Antonyms : in this technique, the teacher explains the meaning of a new word by giving its opposite if the students know the word meaning contrary feature, e.g. warm is not cold.

- Definition : relies on giving the definition of a given word. It can be simple, precise or scientific definition .It can also be a definition taken from a dictionary which is a good method in mobilizing students to use dictionaries .

The teaching of lexis, as that of grammar, should help the learner to develop his communicative competence within a significant context. It takes into consideration the learning situations without restricting the use of lexical elements to one specific context or project.The themes are selected in accordance with the learner's age, needs, interests, environment and imagination. Moreover, specific expressions are to be taught in order to provide learner with the convenient means to communicate authentically; they enable him to meet some language needs and can ;therefore, compare these forms with the ones used in his native language ( Arabic) or other foreign languages.

Lexis is a very important element in the usage of language, so it is essential to encourage learners acquire as much vocabulary as possible so as to master a maximum of language elements and then use them to express himself, understand and interpret messages .For example, they have to select appropriate items to do a given task, and accept the fact that in each learning situation they may find unknown vocabulary, but they needn't know or understand the meaning of all words in a given listening or reading passage. However, they should try to predict their meaning according to the context or the situation in which they appear.

The three phases that are adopted in the teaching of grammar are also applied for the teaching of vocabulary :

-Phase one : observation

-Phase two : analysis / construction of rules /practice

-Phase three : synthesis / re-investment /re-use

Here are some strategies for the pre-teaching of vocabulary when necessary :

- Ask the students to study and examine the context in which the new word appears and predict its meaning by studying its position and function within the sentence .

- The use of definitions, mimes, synonyms, antonyms, examples, are more efficient than direct explanations. 
- The use of a dictionary is to be avoided in the classroom unless it is part of the instruction.

- Review of vocabulary is interesting and useful; it can take the form of a table including the list of words which have been learnt, e.g. the teacher can ask her/his students about what they have learnt this week, and the students write down the words they have learnt on the board, in this way the teacher can check, consolidate and corrects the students' mistakes .

A personal vocabulary note-book or words bank is of great importance to the learners who can use it in their revisions, homework, projects or even for communicating inside and outside the classroom . Of course, the teacher ought to control this note-book so as to correct any spelling mistakes.

\section{Results and Discussion}

The teaching of English as a Foreign Language in the Algerian schools aims to develop communicative, linguistic, cultural and methodological skills. The ultimate objective of the teaching and learning process in the EFL classroom is the developments of the four basic language skills as well as language components.It implements the competency-based approach that contributes a lot in enriching the quality of this process as it enables to :

-give a meaning to learning situations;

- make learning more effective ;

-found future learning situations ;

-integrate primary, intellectual and social skills.

\section{-Give a meaning to learning situations:}

Competencies development aims at giving a meaning to learning situations, and putting them in contexts. It also aims at locating learning in comparison to a given situation which is meaningful for the pupil. Accordingly, knowledge should not remain theoretical for the pupil, but it should rather serve him in his school or familiar milieu, and even in his adult life later on (as a worker or a citizen ).

\section{-Make learning more effective:}

First of all ,EFL teaching and learning process is geared towards the stabilization of the acquired knowledge . Indeed, problem solving situations is an important component the of learning process to fix knowledge or skills. It favours problem solving situations by giving the pupil the opportunity to mobilize his knowledge in increasingly new situations. Moreover, it puts emphasis on the most important parts of learning. In fact, the latter has different levels; some of them are important because they are useful in daily life situations or they constitute the fundamental principles of following learning situations. Finally, competencies development leads to establish a link between the different concepts related to a specific subject and those related to different subjects .

\section{- Found future learning situations:}

The progressive connection between the different types of pupil's knowledge and skills, and the mobilization of the latter in significant situations require more than one school year or one class. This connection helps also in the construction of a global system in which the acquired knowledge and abilities are increasingly reinvested from one level to another; they are also put at the disposal of more complex competencies. Therefore, it paves the way to future learning ( Roegiers 2001:77).

\section{-Integrate primary, intellectual and social skills}

The pedagogy of integration that is implemented in the EFL classroom does not seek to develop discrete language skills separately. It aims, however, at promoting a range of multiple skills all together at the same time, not only primary skills but intellectual and social skills as well. Nowadays, it seems to be an appropriate solution since it provides the learners with meaningful situations and make their learning more effective, even those who are slow or live in poor countries where school failure rate is enormous. The objectives is therefore to integrate learners in active life as well as daily life (L'éducateur 2006:12).

\section{Conclusion}

The main aim of this study was to shed light on the teaching and learning process in the Algerian EFL classroom and its role in developing a reflective, creative and responsible thought by involving two partners who work together for the success and effectiveness of this interrelationship. The first partner is the teacher as an agent of change. The second is the learner, the one subjected to this change. The findings indicate that each partner in the pedagogical couple has got his own role, needs and characteristics. Between these two partners, there is a sort of educational contact or a common aim that is success. The nature of this success is determined by the educational system in which they are involved, including the teaching and learning conditions and the problems encountered. Language teaching and learning process aim primarily at stabilizing the acquired knowledge and reinvest it in learners' daily life. That knowledge should not remain theoretical for the learner, but it should rather serve him in his school or familiar milieu and even in his adult life later on as a worker or a citizen. When this objective is reached, language 
teaching and learning process is said to be effective. Hence, researchers are urged to find a better way to motivate learners and develop their learning styles and strategies by taking into consideration the EFL classroom situation in which the teaching and learning process is taking place.

Funding: "This research received no external funding"

Acknowledgments: The author would like to thank the editorial board of the International Journal for Language, Literature and Translation (IJLLT) for their support to researchers from all over the world.

Conflicts of Interest:"The author declare no conflict of interest".

\section{References}

[1] Cela, M . N .(1994). Interaction and communication in the ESOL classroom .English Teaching Forum . XXII/2.

[2] Davis, E .(1994). Helping teachers and students understand learning styles .English Teaching Forum . 32/3.

[3] Document d'Accompagnement du Programme d'Anglais de Deuxième Année Secondaire. (2006). Alger,Algérie : Office National des Publications Scolaires.

[4] Ernestova, M .(1989). How to use reading made pictures . English Teaching Forum. 14/4.

[5] Garinger ,D .(2001).Textbook evaluation. TEFL Web Journal. Retrieved from: http://www.teflweb-j.org/vlnl / garinger.html

[6] Harmer, J .(2001). The Practice of English Language Teaching ( $3^{\text {rd }}$ Edn). Essex :Pearson Education Limited.

[7] Hudson, R.A. (1980). Sociolinguistics. Cambridge :CUP.

[8] Larsen-Freeman, D. (2000). Techniques and Principles in Language Teaching( $2^{\text {nd }}$ Edn ) . Oxford :OUP.

[9] L'éducateur.(2006). La pédagogie de l'intégration. №5..Ministere de l'éducation Nationale ,Algérie

[10] Litz, D. R. A. (2001). Textbook evaluation and ELT management : A South Korean case study. Retrieved from: www.asian-efljournal.com/Litz thesis .pdf

[11] Lyons, J. (1981). Language and Linguistics . Cambridge :CUP

[12] -Nunan, D. (1988) The Learner Centered Curriculum. Cambridge: Cambridge University Press.

[13] Nunan, D . (2003). Designing Tasks for the Communicative Classroom. Cambridge: Cambridge University Press.

[14] Programme d'Anglais de Première Année Secondaire.( 2005). Alger, Office National des Publications Scolaires .

[15] Referential Guides Service . (2001).Effective teaching. Algiers, Algeria :TheNational Centre of Pedagogical Documantation

[16] Rivers, W. (1970). Teaching Foreign Language Skills. Chicago and London: The University of Chicago Press.

[17] Roegiers, X. (2001). Une Pédagogie de l'Intégration, Compétences et Intégration des Acquis dans l'Enseignement( $2^{\text {nd }}$ Edn). De Boock université.

[18] Shuman, K .(1997). Factors to consider. English Teaching Forum .35/ 3.

[19] Teacher's Book Getting Through : Secondary Education Year Two.(2006). Algeria,The National Authority for School Publications .

[20] The World Book Encyclopedia .(1983). USA : Ascott Fetzer Company .

[21] Venkateswarn, S. (1995). Principles of Teaching English. Delhi: Modern Printers. 